\title{
Post-truth era and impact on the science associated with sport and exercise medicine
}

We have entered an era in public life where truth has lost its status. Truth is no longer the pinnacle that we strive for to settle debates, make decisions and drive policy. Facts are conveniently twisted, shaped, and even created. This is most evident when we see politicians disregarding the truth in the determination of important decisions. They also draw upon their followers' emotions to deceive them to push their political agendas. Any challenge to the factual basis of their argument is met with an aggressive response, which often includes the words such as "fake news"- a deliberate spread of misinformation. This is well characterised in all sectors of society, not only in politics, and is known as the "post-truth" era. The term 'post-truth'was the Oxford Dictionaries Word of the Year in 2016. [1] The awards for Word of the Year are reserved for words that have attracted a great deal of interest in that particular year. 'Posttruth' is an adjective defined as 'relating to or denoting circumstances in which objective facts are less influential in shaping public opinion than appeals to emotion and personal belief'. ${ }^{[1]}$ It is concerning that the new term, 'post-truth' that describes this negative trend in society was recognised with this international award. Compare this to the Word of the Year for 2015 (emoji, a pictograph, also known as the Face with Tears of Joy) or 2013 (selfie, a picture taken of oneself typically with a smartphone or webcam) - both innocuous in comparison to 'post-truth'.

Scholars have tried to explain the factors that have caused this phenomenon of post-truth. The easy access to social media, blogs and internet stories are largely to blame. We have seen this strategy used in the presidential campaigns in America. There are also examples of post-truth propaganda in South Africa where groups with a political agenda are sponsored to tweet untrue stories in support of this agenda. [2]

Are scientists protected from this trend? It seems so because there are many checks and balances built into the propagation of knowledge through the scientific process. Studies have to go through an Institutional Review Board for ethical clearance, and research findings have to be reviewed before they get published. Once papers are published they are open to scrutiny by the scientific community. These points alone convey some checks and balances to the distribution of facts that are not entirely true. However, despite this system that is designed to self-correct, scientists should not sit back and assume that the post-truth era is not going to influence the well-established scientific process. A problem threatening this process is the emergence of predatory journals. [3] The business model of predatory journal use contributes to the short circuiting of the established scientific process. Predatory journals make authors pay for having their papers published. The submitted papers may undergo peer review, but the process is accelerated and the acceptance rate is high compared to that of the more legitimate journals, which reject about $80-90 \%$ of the submitted papers. Predatory journals can be easily identified because they usually canvas for papers in an aggressive manner. The predatory journal often has a title that is similar to an established journal. They have editorial boards (some members have fake names) to provide some authenticity. Sometimes academics are listed on the editorial board without ever having been formally invited or notified. The business model works for some, particularly the scientists who are under pressure from their academic institutions to publish. They are prepared to pay this price. Others publish their material in these journals not realising that the journal is dubious. The increase of predatory journals is not a passing trend. Their publication volumes increased from 53000 in 2010 to an estimated 420000 articles in 2014. [4] There are about 8000 active predatory journals at present, with many of these in the health, exercise and sports medicine disciplines. ${ }^{[4]}$

Scientists need to guard against the abuse of the scientific process which occurs when they publish in predatory journals. There also needs to be a concerted effort to educate nonscientists on how to understand scientific claims. This has been attempted by the authors of a paper which lists 20 points which non-scientists should understand. ${ }^{[5]}$ Examples of these points in the paper include: Differences and chance cause variation, Bias is rife, Controls are important, Correlation does not imply causation, Extrapolating beyond the data is risky and Data can be dredged or cherry-picked. A better understanding of these and the other points mentioned in the paper, will make a contribution to the preservation of the scientific process. Consumers of scientific papers, whether they be scientists, journalists, politicians, or members of the public will be better equipped to interpret the quality of the information if they have these basic skills.

Another way of protecting the scientific process is to disregard papers that represent poorly designed experiments. This includes studies with a low sample size, inadequate control and poor ecological validity. Sometimes good journals let low quality studies slip through the review process - these poor quality papers should not be cited in other research, unless they are being used as an example of poor research. Papers from predatory journals should be treated with caution and not cited unless the paper has been scrutinised for quality. Without these filters we will rapidly head towards a post-truth era, with fake data polluting real data. The outcome of this scenario is gloomy.

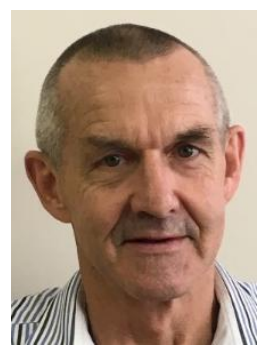

\section{Mike Lambert}

Editor-in-chief

\section{S Afr J Sports Med 2016;28(3):63. DOI: 10.17159/2078-516X/2016/v28i3a1838}

\section{References}

1. Word of the Year 2016 is... https://en.oxforddictionaries.com/word-of-theyear/word-of-the-year-2016 (accessed 26th February, 2017)

2. JUSTICE MALALA: The truth behind the 'white monopoly capital propaganda assault. https://www.businesslive.co.za/rdm/politics/2017-01 23-justice-malala-the-truth-behind-the-white-monopoly-capital-propagandaassault (accessed 26th February, 2017)

3. Beall J. Predatory publishers are corrupting open access. Nature 2012 489(7415):179. [http://dx.doi.org/10.1038/489179a]

4. Shen C, Björk B-C. 'Predatory' open access: a longitudinal study of article volumes and market characteristics. BMC Med 2015; 13:230 [.doi.org/10.1186/s12916-015-0469-2]

5. Sutherland WJ, Spiegelhalter D, Burgman MA. Policy: Twenty tips for interpreting scientific claims. Nature 2013; 503(7476), 335-337. [doi.org/10.1038/503335a] 